\title{
Organizational boundaries of medical practice: the case of physician ownership of ancillary services
}

\author{
John E Schneider ${ }^{1,3^{*}}$, Robert L Ohsfeldt ${ }^{1,2}$, Cara M Scheibling ${ }^{1}$ and Sarah A Jeffers ${ }^{1}$
}

\begin{abstract}
Physician ownership of in-office ancillary services (IOASs) has come under increasing scrutiny. Advocates of argue that IOASs allow physicians to supervise the quality and coordination of care. Critics have argued that IOASs create financial incentives for physicians to increase ancillary service volume. In this paper we develop a conceptual framework to evaluate the tradeoffs associated with physician ownership of IOASs. There is some evidence supporting the existence of scope and transaction economies in IOASs. Improvement in flow and continuity of care are likely to generate scope economies and improvements in quality monitoring and reductions in consumer transaction costs are likely to generate transaction economies. Other factors include the capture of upstream and downstream profits, but these incentives are likely to be small compared to scope and transaction economies. Policy debates on the merits of IOASs should include an explicit assessment of these tradeoffs.

This research was supported in part by funding from the American Association of Orthopaedic Surgeons (AAOS).
\end{abstract}

\section{Background}

In recent years there has been considerable attention devoted to physician ownership of health-care related assets, with concerns raised over the effects of incentives associated with hospital ownership [1-7], ambulatory surgery center (ASC) ownership [8-10], and ancillary service ownership [11-14]. Ancillary ownership has been the focus of several recently published articles, and has been the focus of some state-led policy initiatives aimed at restricting physician ownership. ${ }^{a}$ Ancillary ownership generally includes ownership of free-standing ancillary services, such as imaging centers, as well as in-office ancillary services (IOASs), which typically includes standard imaging, advanced imaging, ultrasound, clinical laboratory, and outpatient therapy (e.g., occupational and physical therapy) [14].

In 1989 Congress adopted the Ethics in Patient Referrals Act, commonly referred to as Stark I, which went into effect on January 1, 1992. Stark I was amended in 1993, with the new amendments referred to as Stark II, going into effect on January 1, 1995. Stark II added some additional health services to the self-referral prohibition, extended the prohibitions to Medicaid, and clarified conditions for exceptions. The law was amended for

\footnotetext{
* Correspondence: john.schneider@oxfordoutcomes.com

'Oxford Outcomes Ltd., Morristown, USA

Full list of author information is available at the end of the article
}

a third time, with the new amendments referred to as Stark III, going into effect on December 4, 2007. Together, the current -Stark" laws prohibit physicians from referring Medicare patients to entities for certain -designated health services" if the physician, or an immediate family member of the physician, has a financial relationship with the entity. Financial relationships are broadly defined to include investment and ownership interests, as well as compensation arrangements between a physician, or his/her family member, and an entity [15-18].

The IOAS exception to Stark allows physicians to own in-office ancillary services. However, according to critics, the IOAS exception has created a loop-hole in the referral system and has contributed to recent growth in the utilization of in-office ancillary services [14,19-23]. Advocates of the IOAS exception say that the IOAS's purpose is to permit physicians to supervise the quality of care, to allow for better coordination among patients, physicians, and ancillary services, and to provide incentives for patients to adhere to recommended treatment plans. On the other hand, it has been argued that the exception creates financial incentives for physicians to increase the volume of services provided [14].

The purpose of this paper is to develop a conceptual framework through which to critically evaluate the tradeoffs associated with physician ownership of IOASs. 
Throughout the paper we use as an example the case of orthopaedic surgery practice ownership of imaging and physical therapy (PT). This case serves as a good example for two reasons. First, imaging and physical therapy are critical components of the orthopaedic continuum of care [24-28]. Second, orthopaedic surgeon ownership of imaging services has become a relatively common target of critics of physician ownership of ancillary services and medical facilities [13,29-36]. To explore the question of whether IOASs are -good or bad," the full set of tradeoffs should be considered. Setting aside the political aspects of the debate, the IOAS issue is an example of a common organizational problem faced by firms: whether to -make or buy" various stages of the production process.

\section{Boundaries of physician practice}

The relationship between orthopaedic practices and ancillary services can be viewed as a -vertical relationship," where imaging can be viewed as an -upstream" service and physical therapy can be viewed as a -downstream" service relative to orthopaedic treatment (Figure $1)$. Vertical relationships can be organized through market-based contractual arrangements or through vertical integration, wherein the medical practice obtains imaging and therapy services via direct ownership.

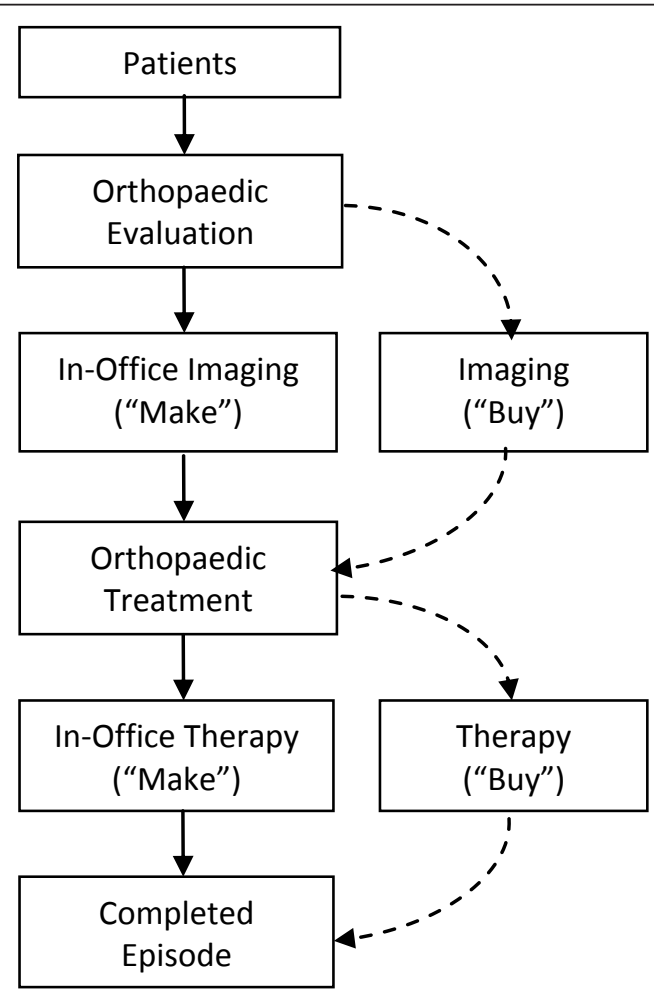

Figure 1 Vertical Relationships in Orthopaedic Practices.
The boundaries of firms-in this case whether medical practices should -make or buy" ancillary services-are a function of a variety of factors, mainly scope economies and transaction economies [37-43]. These factors can be thought of as -organic" drivers of the boundaries and scope of firms; the existence of these factors compels firms to adopt purposeful forms of organization designed to minimize operating costs and maximize comparative advantage. The following sections discuss these factors in more detail and in the context of orthopaedic medical practice and ancillary services.

\section{Economies of scope}

Cases where the costs of conjoint production are lower than the costs of separate production are said to exhibit economies of scope, [44] and economies of scope are an important determinant of organizational boundaries $[45,46]$. Economies of scope are likely to be present when production relies on a common set of resources, such as technology, core competencies, and dual-use labor and capital inputs. Core competencies are particularly relevant to health care organizations, which rely disproportionately on highly trained human capital. Core competencies refer to firms' stock of knowledge assets (including tacit knowledge and know-how), skills, capabilities, learning processes, and resources. By diversifying and expanding into activities that are related to core competencies, firms are able to take better advantage of knowledge sharing, learning processes, and improved managerial efficiency [47-49].

Concentrating on scope economies and core competencies enhances the learning process by assuring that decision-making situations are repeated in sufficiently large numbers [50]. The role of learning depends on the ability of the firm to process information during the production process and apply the information appropriately. The learning process is critical to the formation and adaptation of organizational routines, which include rules of thumb, guidelines, templates, and protocols [51]. Specialized routines are the subcomponents of organizational -know how" and core competencies and are often sources of comparative advantage and production economies [52-54].

There are several aspects of orthopaedic IOASs that suggest the presence of economies of scope. Aiken et al. (2008) found that when orthopaedic surgeons work closely with PTs they were more likely to recommend nonsurgical treatment options [55]. This finding was also observed during wartime, when military orthopaedic surgeons facing increasing caseloads were able to treat a larger volume of patients by triaging cases between surgical and non-surgical treatment pathways [56]. Similarly, there appear to be synergies associated with interdisciplinary teams conducting rounds at hospitals. 
In a study by Dutton et al. (2003), multidisciplinary hospital rounds for trauma patients included trauma center physicians, orthopaedic surgeons, physical therapists, and other members of the trauma care team [57]. The study found that the implementation of interdisciplinary teams reduced hospital lengths of stay by $36 \%$.

The synergies observed in interdisciplinary teams are attributable in part to improved information flow. There are likely to be considerable benefits associated with improved flow of clinical information among members of the patient care team (orthopaedic surgeons, physical therapists, physician assistants, nurses, etc.) and between the care team and the patient. Often referred to as -corridor consultations," physicians and PTs can consult with one another with very little scheduling or planning [58].

One example of the benefits of better PT-physician communication is order clarification. There is some evidence that physicians typically provide non-specific and sometimes unclear referral diagnoses to PTs; according to one study, only $32 \%$ of physician referrals were judged to contain critical information regarding anatomy and pathology [59]. Orthopaedic surgeons and PTs practicing together have the potential to reduce these inefficiencies in knowledge transfer and face few impediments to doing so. In addition, physicians tend to underestimate pain and overestimate functioning [60], which suggests potential benefits from improved posttreatment communication between patients and physicians; in-office PTs offer a conduit for this type of information feedback.

\section{Transaction costs}

There are two limitations to relying on scope economies alone to explain organizational boundaries. First, scope economies do not imply ownership; alternative forms of organization can be designed to capture economies of scope. Second, scope economies apply only to production technology and processes, and do not take into account demand-side factors. Transaction cost economics, however, has the advantage of addressing both supply and demand factors, and extends beyond scope and scale economies by focusing on the transaction as the unit of analysis $[37,38,61,62]$. The theoretical basis of transaction cost economics is that the boundaries of organizations are in part a function of the nature of the business transacted, where relatively complex transactions are more efficiently organized in settings that feature stronger administrative controls. Transaction complexity is a function of several factors; in health care settings, the most prominent forms of transaction complexity are uncertainty and imperfect information [63]. Uncertainty and imperfect information lead to increased production costs on the part of suppliers and increased search costs on the part of consumers.

All forms of governance exhibit strengths and weaknesses in organizing transactions. Uncomplicated transactions can be handled efficiently by organizational forms that lack strong controls, such as commodity markets and simple contracts. However, as transactions become more complex, they are most efficiently organized within forms of governance that offer stronger controls. In some cases, the most efficient means of organizing complex transactions is via full integration through ownership. The advantages of administrative controls, however, must be traded off with the increased bureaucratic costs associated with integration and, in the case of orthopaedic surgery practices owning IOASs, the possibility of added expenditures due to increased utilization.

In the market for medical care, consumer transaction costs are the costs incurred by the consumer to complete a transaction, including the time necessary to implement informed choice, such as evaluating, choosing and locating a care provider, as well as the time spent directly obtaining the services. Obtaining medical care requires non-trivial time input on the part of consumers, particular those over the age of 65 . Based on our analysis of the 2009 American Time Use Survey (ATUS), Americans over the age of 65 devote approximately 108 hours per year in the primary activity of obtaining medical care services, including time spent obtaining, receiving, and purchasing services. Applying a median wage to this age group of $\$ 20$ per hour,[64] this amounts to approximately $\$ 2,160$ per person per year, or about $12 \%$ of total per capita medical care spending for the age group [65]. The effort required to obtain medical care is also reflected to some degree in -ease of access" measures. The Agency for Healthcare Research and Quality's report on National Health Disparities reported that $60-70 \%$ of the insured population -perceived difficulties or delays in obtaining care and problems getting care as soon as it is wanted." [66]

Although unmet need and pent-up demand are difficult to measure directly, there is some indication that these factors are important in IOAS demand and utilization. For example, in the case of PT, according to one study the proportion of patients with perceived need for PT but receiving no PT services increased during the two-year post-discharge period from $23 \%$ to $68 \%$, suggesting substantial unmet need in physical therapy that increased with time from discharge [67]. In the case of imaging, the issue has more to do with the wide range of factors driving imaging decisions than unmet imaging need. For example, Carey and Garrett (1996) found that the use of CT and MRI for low back pain patients was 
associated primarily with patient characteristics, such as baseline functional status [68].

IOASs can be viewed to a certain extent as a response to these transaction costs. In the case of PT, these costs include finding a PT (or a set of potential or -feasible" PTs), determining the quality of the PT, determining the location of the practice and traveling to the facility. Consumer transaction costs are expected to be lower in the case of IOASs because patients have ready access to ancillary services and have the opportunity to economize on indentifying, vetting, locating and traveling to a provider [69]. In addition, there are several conveniencerelated benefits associated with IOASs, including easier scheduling, enhanced adherence to treatment plans [70,71], and -one-stop shopping." [58,72-75]

The latter benefit has been challenged in a recent study by Sunshine and Bhargavan (2010), who examined Medicare claims showing a visit to a specialist (an -index" visit) followed by an imaging claim associate with the same physician (i.e., a self-referred imaging service) [36]. The authors found that $74 \%$ of self-referred $\mathrm{x}$-rays were conducted on the same day as the index visit, but only $15 \%$ of CTs and MRIs were conducted on the same day. The authors conclude that these data imply the absence of a -one-stop shopping" benefit to consumers, especially for CT and MRI. However, the study has two significant limitations. First, there is clearly a one-stop shopping benefit associated with some ancillary services, such as $\mathrm{x}$-ray and ultrasound, which are relatively quick procedures unlikely to prolong an office visit. Second, the findings on CT and MRI most likely reflect the fact that advanced imaging requires more time, and prolonging a visit is not necessarily feasible for time-constrained patients. Moreover, these data do not reflect the likely convenience associated with on-site scheduling of CT and MRI scans and the reduced search costs associated with follow-up care (e.g., choosing providers, locating providers, and determining managed care network status).

Another important aspect of transaction economies is that medical care embodies -temporal specificities" in that diagnosis and treatment outcomes depend not only on which diagnostic test or treatment is performed, but also when the diagnosis or treatment is performed. Diagnosis and treatment timing is dependent on a variety of factors, including disease progression and symptoms, availability of providers, and patient adherence to treatment plans. For example, Gilbert et al. (2004) conducted a randomized controlled trial of patients with low back pain, and found that patients who received -early" imaging had better clinical outcomes than those who did not receive early imaging [27]. IOASs are a means of optimizing the timing of diagnostic testing (in the case of in-office imaging) and treatment (in the case of in-office PT).

\section{Other factors}

Scope economies and transaction economies are the main drivers of vertical integration [43,76]. However, in some cases the motivation to vertically integrate may be driven simply by a desire to capture the profits of upstream and downstream firms. This view of vertical integration is the least prominent determinant of organizational boundaries, primarily because it lacks a -corporate coherence" component; [77] that is, were firms simply interested in acquiring profitable entities, the ownership of any profitable enterprise would suffice, and ownership of stocks, bonds and securitized assets are more convenient means of earning returns from profitable enterprises.

Nevertheless, critics of physician ownership of IOASs focus on this rationale in their depiction of vertical integration among medical practices and ancillary services. The crux of the argument is that asymmetrical and imperfect information allow some types of service professionals to -induce" demand for their services; that is, suppliers, -experts" in particular, have the ability to shift the demand curves of their customers $[78,79]$. In the medical care context, supplier-induced demand (SID) is defined as -the effect that doctors (or some other group of professionals), as providers of services, may have in creating more patient demand than there would be if they acted as perfect agents for their patients."[[80], p.333] Whereas several of the earlier studies of physician SID were hampered by study design and endogeneity problems (for a critique refer to Dranove and Wehner [81]), more recent studies controlling for endogeneity suggest that physicians are able to induce demand for their services to some extent, depending on the type of services and payment mechanisms [78,82-84].

There are two important limitations of relying on SID as a theoretical basis for understanding the effects of ownership. First, the better designed SID studies do not draw clear distinctions between differences in vertical relationships. Does full integration (via ownership) provide stronger inducement incentives than other forms of vertical relationships, such as joint ventures and longterm contracts? Afendulis and Kessler (2006) considered interventional cardiologists (i.e., those who perform diagnostic procedures and surgical treatment) as vertically integrated entities, and found that interventional cardiologists appear to be able to induce demand for angioplasty. However, their study did not distinguish among cardiologists who are full or part owners of cardiac catheterization facilities from those who utilize non-owned facilities via contract, such as hospitalowned facilities.

The second limitation of employing SID to critique integrated IOASs is that third-party payment mechanisms have evolved considerably in the past decade, and 
now typically contain a variety of administrative controls on utilization and payment. When coupled with the rapid diffusion of easily-accessible medical information and better-informed patients, administrative controls have placed limits on the intensity of SID [85-89]. In some managed care settings, ancillary service referrals require pre-authorization or pre-certification. This is especially true in the case of advanced imaging, such as CT and MRI. Thus, given that the literature generally indicates that the pre-certification process is effective in terms of reducing unnecessary services, [90-93] due to the -sentinel" effect of pre-certification review, it is unlikely that a substantial proportion of pre-certified or preauthorized CTs or MRIs could be considered inappropriate.

It is also important to note that, empirically, it is difficult for researchers to accurately assess the clinical appropriateness of what may appear to be induced demand. Much of the research on ancillary service utilization is limited by inadequate controls for case mix severity and other demand factors. Consequently, these studies offer little evidence that higher utilization rates resulting from self-referral to ancillary services represent inappropriate or unnecessary care [94-96]. Thus, it is possible that increases in utilization in part reflect -pent-up" demand for services (i.e., services that would have been performed at higher rates prior to integration were there to have been sufficient capacity) rather than inappropriate care. For example, Restuccia et al. (1996) assessed whether the rate of inappropriate hospital admissions is higher in areas with higher rates of hospital admissions. Seventy small geographic areas were formed by grouping Massachusetts ZIP codes by similarity of hospital use [97].

Appropriateness of hospital admission was measured by applying an appropriateness protocol combined with physician judgment based on chart review. The authors found no relationship between hospital admission rates and inappropriate admission rates, calling into question the common assumption that areas with higher hospital use have more inappropriate use of hospital care.

Appropriateness also appears to be insensitive to financial incentives, even on the part of price-sensitive consumers $[98,99]$. Underscoring the fact that inappropriate care is a by-product of any medical care transaction, a study of the U.S. Veterans Health Administration (VA) hospital system found evidence of relatively high levels of inappropriate care in spite of the lack of financial incentives to physicians associated with VA hospital admissions [100]. Indeed, in their frequently cited study on IOAS ownership, Mitchell and Scott (1992) concede that -none of the studies to date...has been able to determine whether the increased utilization...represents inappropriate or unwarranted services."[34]
Finally, another important consideration is that IOAS integration implies the incurring of the operating costs of the acquired entity. In order to directly employ PTs, for example, orthopaedic surgeons must pay market salaries (which average approximately $\$ 72,900$; see [101]). However, it is likely that salaried PTs will have somewhat lower productivity than self-employed PTs [12,102-104]. Thus, an orthopaedic surgery practice will have the same costs but earn less revenue than selfemployed PT practices, the net result of which will be lower operating margins on PT services provided through the orthopaedic practice. Moreover, when compared to surgeons' own marginal revenue on resourceintensive procedures such as hip and knee replacement, it is unlikely that low operating margins on ancillary services provide sufficient financial incentives to invest in IOASs. For all services performed by orthopaedic surgeons, the $50^{\text {th }}$ percentile (median) billing rate per service is approximately $\$ 2,300$, compared to a median billing rate per service of only $\$ 94$ for PT (based on data reported in [105]).

\section{Discussion}

The preceding section focused on two of the most commonly cited reasons for vertical integration-scope economies and transaction economies. Scope economies are likely to be an important factor in IOAS integration because of the potential to improve the flow and continuity of medical care. There is some evidence of scope economies in the case of physician integration into outpatient therapy. Transaction economies are also important to the integration decision, providing incentives for physicians to monitor quality (including the timing of ancillary services) and incentives for consumers to reduce the costs associated with obtaining medical care. There is some evidence of transaction economies in the case of physician integration into imaging and outpatient therapy. Other factors potentially influencing integration decisions include the capture of upstream and downstream profits, but these incentives are likely to be small compared to scope and transaction economies.

This leads to the pivotal policy question regarding tradeoffs: Are the economic benefits of integration worth the potential costs incurred through demand inducement and overutilization? To some extent policy makers have answered this question by passing a variety of laws restricting ownership, such as the Stark laws and the recently enacted federal Affordable Care Act (ACA), which places limits on physician ownership of acutecare hospitals. However, the language of these laws, and the content of the deliberations preceding the laws, generally lack explicit discussions of tradeoffs. Instead, the principal rationale has been simply that ownership leads to higher rates of demand inducement. In light of the 
preceding discussion, we argue that this view is too narrow, and has not allowed for the consideration of the benefits of integration.

The latter point is worth emphasizing given the rapid change in physician organizational arrangements over the past decade [106-110]. Imperfect agency is a central tenet of SID, but there are many factors that cause physicians to act as imperfect agents for their patients, including, for example: (1) information asymmetry between patient and physician; (2) financial incentives associated with third-party payment mechanisms; and (3) physician associations and business relationships (e. g., joint ventures and other collaborative arrangements; granting of admitting privileges; etc.) with medical groups, practice associations, and hospitals. Each one of these factors is enough to move physicians away from -perfect" agency on behalf of patients and toward some degree of imperfect agency [111-114]. The implication is that it is not simply ownership that influences clinical decision making and referral patterns, but a host of factors that are present in a variety of vertical relationships-not limited to vertical integration.

\section{Conclusions}

The recent resurgence of controversy surrounding orthopaedic surgeon ownership of IOASs has been driven by a handful of studies, some of which have shown an association between orthopaedic surgeon ownership of IOAS and utilization of the owned services. In this paper we put forward a more balanced assessment of the tradeoffs associated with vertical integration in general and orthopaedic ownership of IOASs specifically.

Our main conclusions can be summarized as follows. First, any assessment of the effects of vertical integration should account for the full set of tradeoffs associated therewith, including the role of scope and transaction economies. One limitation of our paper is that we do not attempt to empirically measure these economies, and rely instead on anecdotal evidence in the literature. Future studies of physician integration into IOASs should measure these effects and present a more complete accounting of the tradeoffs.

Second, there is little upon which to base the assumption that SID works differently in ownership arrangements versus other forms of governance, such as joint ventures, long-term contracts, and other tightly coupled arrangements that may share some of the benefits of full integration. A limitation of the extant literature (and of this paper) is a lack of evidence comparing how SID intensity might vary by organizational arrangement. Until such studies are done, researchers should adopt a more conservative stance by allowing for possibility of differential SID effects across different organizational forms of medical care delivery. Similarly, although there have been some well-designed studies of SID in recent years, there is a need for continued methodological vigilance regarding SID studies, particularly with regard to the handling of endogeneity and the definition of ownership.

Third, even where these common empirical problems are overcome, the task of identifying the appropriateness of ancillary service use remains an important research challenge. Whether IOAS ownership is undesirable depends a great deal on whether induced services represent appropriate or inappropriate care. Given the lack of consistent findings on inappropriate care in other settings, there appears to be considerable room for further research on the extent to which added ancillary services are appropriate or inappropriate.

\section{Endnotes}

${ }^{a}$ For example, refer to Maryland Court of Appeals decision in Potomac Valley Orthopaedic Associates, et al. v. Maryland State Board of Physicians et al. (January 2011).

\section{Author details}

${ }^{1}$ Oxford Outcomes Ltd., Morristown, USA ${ }^{2}$ Texas A\&M Health Sciences, Department of Health Management and Policy, College Station, USA ${ }^{3}$ Senior Director, Health Economics, Oxford Outcomes Ltd., 161 Madison Avenue Suite 205, Morristown, NJ 07960, USA

Received: 9 June 2011 Accepted: 5 April 2012 Published: 5 April 2012

\section{References}

1. American Hospital Association: Impact of limited-service providers on communities and full-service hospitals. Trendwatch 2004, 6(2):1-8.

2. Casalino LP, Devers KJ, Brewster LR: Focused factories? Physician-owned specialty facilities. Health Aff 2003, 22(6):56-57.

3. Fine A: The specter of specialty hospitals, part I Hospitals \& Health Networks; 2004.

4. Iglehart JK: The emergence of physician-owned specialty hospitals. $N$ Engl J Med 2005, 352(1):78-84.

5. Kahn CN: Intolerable risk, irreparable harm: the legacy of physicianowned specialty hospitals. Health Aff 2006, 25(1):130-133.

6. Kimbol AS: The debate over specialty hospitals: how physician-hospital relationships have reached a new fault line over these "focused factories". J Health Law 2005, 38(4):633-672.

7. Mitchell JM: Do financial incentives linked to ownership of specialty hospitals affect physicians' practice patterns? Med Care 2008, 46(7):732-737.

8. Gabel JR, et al: Where do I send thee? Does physician-ownership affect referral patterns to ambulatory surgery centers? Health Aff 2008, 27(3): w165-w174.

9. Hollingsworth $\mathrm{JM}$, et al: Physician-ownership of ambulatory surgery centers linked to higher volume of surgeries. Health Aff 2010, 29(4):683-689.

10. Mitchell JM: Effect of physician ownership of specialty hospitals and ambulatory surgery centers on frequency of use of outpatient orthopedic surgery. Arch Surg 2010, 145(8):732-738.

11. Cicka MP: Physician ownership and use of in-office advanced diagnostic imaging equipment: are IDTF standards a meaningful response to overutilization, quality, and costs? J Health Life Sci Law 2009, 2(2):161, 163-86.

12. Hollingsworth $J M$, et al: Imaging use among employed and selfemployed urologists. J Urol 2010, 184(6):2480-2484.

13. Levin DC, et al: Ownership or leasing of MRI facilities by nonradiologist physicians is a rapidly growing trend. J Am Coll Radiol 2008, 5(2):105-109. 
14. MedPAC: Report to the Congress: Aligning Incentives in Medicare Washington: Medicare Payment Advisory Commission; 2010.

15. Pursell $D$, et al: Stark II and physician compensation models: integrating business and legal issues. J Health Law 2005, 38(1):45-76.

16. Sandrick K, Stark Laws: Then and Now. Trustee 2008, 61(2):33-35.

17. Stout SM, Warner DC: How did physician ownership become a federal case? the stark amendments and their prospects. HEC Forum 2003, 15(2):171-187.

18. Tayon KJ: Key changes and new interpretations involving the Phase III regulations. J Health Care Compliance 2008, 10(1):13-73.

19. MedPAC: Impact of physician self-referral on use of imaging services within an episode. 2009, Chapter 4.

20. MedPAC: Report to Congress: Improving incentives in the Medicare program Washington: MedPAC; 2009.

21. MedPAC: Report to Congress: Medicare Payment Policy Washington: MedPAC; 2009.

22. Hillman BJ, Goldsmith J: Imaging: the self-referral boom and the ongoing search for effective policies to contain it. Health Affairs 2010, 2231-2236.

23. Benefits M, Physician Ownership of Medical Equipment: Med Benefits 2011, 28(3):5-6.

24. Bert JM: Ancillary services available to the orthopedic surgeon. Orthop Clin North Am 2008, 39(1):1-4, v.

25. Delitto A, Snyder-Mackler L: The diagnostic process: examples in orthopedic physical therapy. Phys Ther 1995, 75(3):203-211.

26. Freburger JK, Holmes GM, Carey TS: Physician referrals to physical therapy for the treatment of musculoskeletal conditions. Arch Phys Med Rehabil 2003, 84(12):1839-1849.

27. Gilbert FJ, et al: Does early imaging influence management and improve outcome in patients with low back pain? A pragmatic randomised controlled trial. Health Technol Assess 2004, 8(17), iii, 1-iii, 131.

28. Jacofsky D, Lyman J: The efficient delivery of elective orthopedic care. $J$ Arthroplasty 2007, 22(7 Suppl 3):2-5.

29. Baker LC: Acquisition of MRI equipment by doctors drives up imaging use and spending. Health Aff 2010, 29(12):2252-2259.

30. Hillman BJ, Goldsmith J: Imaging: the self-referral boom and the ongoing search for effective policies to contain it. Health Aff 2010, 29(12):2231-2236.

31. Hughes DR, Bhargavan M, Sunshine JH: Imaging self-referral associated with higher costs and limited impact on duration of illness. Health Aff 2010, 29(12):2244-2251.

32. Levin DC, et al: Ownership or leasing of CT scanners by nonradiologist physicians: a rapidly growing trend that raises concern about selfreferral. J Am Coll Radiol 2008, 5(12):1206-1209.

33. Mitchell JM, Sass TR: Physician ownership of ancillary services: indirect demand inducement or quality assurance? J Health Econ 1995, 14(3):263-289.

34. Mitchell JM, Scott E: Physician ownership of physical therapy services. Effects on charges, utilization, profits, and service characteristics. JAMA 1992, 268(15):2055-2059.

35. Romano DH: Self-referral of imaging and increased utilization: some practical perspectives on tackling the dilemma. J Am Coll Radiol 2009, 6(11):773-779.

36. Sunshine J, Bhargavan M: The practice of imaging self-referral does not produce much one-stop service. Health Aff 2010, 29(12):2237-2243.

37. Coase RH: The Nature of the Firm. In The Nature of the Firm: Origins, Evolution, and Development. Edited by: Williamson OE, Winter SG. New York: Oxford University Press; 1993:18-33.

38. Furubotn EG, Richter R: Institutions and Economic Theory: The Contribution of the New Institutional Economics Ann Arbor: The University of Michigan Press; 1997.

39. Milgrom P, Roberts J: Economics, Organization and Management Englewood Cliffs: Prentice Hall; 1992.

40. Teece DJ, Pisano G: The dynamic capabilities of firms: an introduction Ind Corp Change 1994, 3(3):537-556.

41. Williamson OE: Comparative economic organization: the analysis of discrete structural alternatives. Adm Sci Q 1991, 36(2):269-296.

42. Williamson OE: The economics of governance. Am Econ Rev 2005, 95(2):1-18.

43. Perry MK: Vertical Integration: Determinants and Effects. In Handbook of Industrial Organization. Volume 1. Edited by: Schmalensee R, Willig RD. Amsterdam: Elsevier Science Publishers B.V; 1989.
44. Panzar JC, Willig RD: Economies of scope. Am Econ Rev 1981 71(2):268-272.

45. Teece DJ: Economies of scope and the scope of the enterprise. J Econ Behav Organ 1980, 1(3):223-247.

46. Chandler AD: Scale and Scope: The Dynamics of Industrial Capitalism Cambridge: The Belknap Press/Harvard University Press; 1990.

47. Hill CWL: Diversification and Economic Performance: Bringing Structure and Corporate Management Back into the Picture. In Fundamental Issues in Strategy: A Research Agenda. Edited by: Rumelt RP, Schendel DE, Teece DJ. Boston: Harvard Business School Press; 1994:297-321.

48. Danneels $\mathrm{E}$ : The dynamics of product innovation and firm competencies. Strateg Manage 2002, 23:1095-1121.

49. Helfat $C E$, et al: Dynamic Capabilities: Understanding Strategic Change in Organizations Malden: Blackwell Publishing; 2007.

50. Skinner W: The focused factory. Harv Bus Rev 1974, 52(3):113-120

51. Nelson RR, Winter SG: An Evolutionary Theory of Economic Change Cambridge: Belknap; 1982.

52. Chandler AD: Organizational capabilities and the economic history of the industrial enterprise. J Econ Perspect 1992, 6(3):79-100.

53. Wruck KH, Jensen MC: Science, specific knowledge, and total quality management. J Accounting Econ 1994, 18:247-287.

54. Greve HR: Organizational Learning from Performance Feedback: A Behavioral Perspective on Innovation and Change Cambridge: Cambridge University Press; 2003.

55. Aiken $A B$, et al: Easing the burden for joint replacement wait times: the role of the expanded practice physiotherapist. Healthc Q 2008, 11(2):62-66.

56. Davis $S$, Machen MS, Chang L: The beneficial relationship of the colocation of orthopedics and physical therapy in a deployed setting: Operation Iraqi Freedom. Mil Med 2006, 171(3):220-223.

57. Dutton RP, et al: Daily multidisciplinary rounds shorten length of stay for trauma patients. J Trauma 2003, 55(5):913-919.

58. Duxbury P: The physician-owned physical therapy department. Orthop Clin North Am 2008, 39(1), 49-53-vi-vii.

59. Davenport TE, et al: Current status and correlates of physicians' referral diagnoses for physical therapy. J Orthop Sports Phys Ther 2005, 35(9):572-579.

60. Rosenberger $\mathrm{PH}$, et al: Shared decision making, preoperative expectations, and postoperative reality: differences in physician and patient predictions and ratings of knee surgery outcomes. Arthroscopy 2005, 21(5):562-569.

61. Williamson OE: The Mechanisms of Governance New York: Oxford University Press; 1996.

62. Williamson OE: Transaction Cost Economics: The Natural Progression (Nobel Prize Lecture, December 8, 2009). Am Econ Rev 2010, 100(3):673-690.

63. Robinson JC: A New Institutional Economics of Health Care. In The State, Politics, and Health: Essays for Rudolf Klein. Edited by: Day P et al. Cambridge: Blackwell; 1996:.

64. BLS: Usual Weekly Earnings of Wage and Salary Workers: Third Quarter 2011. News Release Washington: Bureau of Labor Statistics; 2011.

65. CMS: National Health Expenditure Fact Sheet Baltimore: U.S. Department of Health and Human Services, Centers for Medicare and Medicaid Services; 2011.

66. AHRQ: National Healthcare Disparities Report: Patient Perception of Need (Data from Medical Expenditure Panel Survey, 2005) AHRQ Pub. No. 09-0002. 2009 Rockville: Agency for Health Care Research and Quality; 2008.

67. Castillo RC, et al: Use and perceived need of physical therapy following severe lower-extremity trauma. Arch Phys Med Rehabil 2005, 86(9):1722-1728

68. Carey TS, Garrett J: Patterns of ordering diagnostic tests for patients with acute low back pain. The North Carolina Back Pain Project. Ann Intern Med 1996, 125(10):807-814.

69. Ogulata SN, et al: Personnel and patient scheduling in the high demanded hospital services: a case study in the physiotherapy service. Med Syst 2008, 32(3):221-228

70. Beattie $P$, et al: Longitudinal continuity of care is associated with high patient satisfaction with physical therapy. Phys Ther 2005, 85(10):1046-1052. 
71. Meijboom BR, Bakx SJWGC, Westert GP: Continuity in health care: lessons from supply chain management. Int J Health Plann Manage 2010, 25(4):304-317.

72. O'Neill W: The physician-owned imaging center. Orthop Clin North Am 2008, 39(1):37-48.

73. Rozich JD, D'Amore L, Sloan J: Physician-owned imaging centers: the future is now. Med Group Manage J 2000, 47(5):48-53.

74. Wallace RA: Physician owned and operated: a good thing. W V Med J 2008, 104(2):4-5.

75. Weeks RB: The physician-owned occupational health department. Orthop Clin North Am 2008, 39(1):55-69, vii.

76. Gozalez-Diaz M, Vazquez L: Make-or-Buy Decisions: A New Institutional Economics Approach. In New Institutional Economics: A Guidebook. Edited by: Brousseau E, Glachant J. Cambridge: Cambridge University Press; 2008:

77. Teece DJ, et al: Understanding corporate coherence: theory and evidence. J Econ Behav Organ 1994, 23:1-30.

78. lizuka T: Experts' agency problems: evidence from the prescription drug market in Japan. Graduate School of International Management, Aoyama Gakuin University 2006.

79. Dulleck U, Kerschbamer R: On doctors, mechanics, and computer specialists: the economics of credence goods. J Econ Lit 2006, 44(1):5-42

80. Culyer AJ: The Dictionary of Health Economics Northampton: Edward Elgar; 2005.

81. Dranove D, Wehner P: Physician-induced demand for childbirths. J Health Econ 1994, 13(1):61-73

82. Afendulis CC, Kessler DP: Tradeoffs from Integrating Diagnosis and Treatment in Markets for Health Care. National Bureau of Economic Research Working Paper Series, No. 12623. Cambridge 2006.

83. Gruber J, Owings M: Physician Financial Incentives and Cesarean Section Delivery. Rand J Econ 1996, 27(1):99-123.

84. Jurges H: Physician-induced demand for medical services in germany: new evidence from conbined district and individual level data. MEAUniversitat Mannheim. Mannheim 2007.

85. Perneger TV, Charvet-Berard A, Perrier A: Patient assessments of the most important medical decision during a hospitalization. $J$ Gen Intern Med 2008, 23(10):1659-1665.

86. Kaplan RM, Frosch DL: Decision making in medicine and health care. Annu Rev Clin Psychol 2005, 1:525-556.

87. Kiesler DJ, Auerbach SM: Optimal matches of patient preferences for information, decision-making and interpersonal behavior: evidence, models and interventions. Patient Educ Couns 2006, 61(3):319-341.

88. Auerbach SM: Do patients want control over their own health care? A review of measures, findings, and research issues. J Health Psychol 2001, 6(2):191-203.

89. Benbassat J, Pilpel D, Tidhar M: Patients' preferences for participation in clinical decision making: A review of published surveys. Behav Med 1998, 24(2):81-88.

90. Blachar A, et al: Preauthorization of CT and MRI examinations: assessment of a managed care preauthorization program based on the ACR appropriateness criteria and the royal college of radiology guidelines. J Am Coll Radiol 2006, 3(11):851-859.

91. Hendel RC: Utilization management of cardiovascular imaging precertification and appropriateness. JACC Cardiovasc Imaging 2008, 1(2):241-248.

92. Smulowitz PB, Ngo L, Epstein SK: The effect of a CT and MR preauthorization program on ED utilization. Am J Emerg Med 2009, 27(3):328-332.

93. Weiner SN, Komarow M: Utilization management and noninvasive diagnostic imaging. Manag Care Interface 2005, 18(5):34-38.

94. Kouri BE, Parsons RG, Alpert HR: Physician self-referral for diagnostic imaging: review of the empiric literature. AJR 2002, 179:843-850

95. Zientek DM: Physician entrepreneurs, self-referral, and conflicts of interest: an overview. HEC Forum 2003, 15(2):111-133.

96. Lurie JD, Bell JE, Weinstein J: What rate of utilization is appropriate in musculoskeletal care? Clin Orthop Relat Res 2009, 467(10):2506-2511.

97. Restuccia J, et al: High hospital admission rates and inappropriate care. Health Aff 1996, 15(4):156-163.

98. Siu AL, Manning WG, Benjamin B: Patient, provider and hospital characteristics associated with inappropriate hospitalization. Am J Public Health 1990, 80(10):1253-1256.
99. Siu $A L$, et al: Inappropriate use of hospitals in a randomized trial of health insurance plans. N Engl J Med 1986, 315(20):1259-1266.

100. Smith CB, et al: Overutilization of acute-care beds in veterans affairs hospitals. Med Care 1996, 34(1):85-96.

101. Bureau of Labor Statistics, Occupational Outlook Handbook: Bureau of Labor Statistics. 2010-11 edition. Washington: U.S. Department of Labor; 2010.

102. Pederson CD: Cause and effect. Understanding the production-profit relationship. MGMA Connex 2007, 7(2):40-45, 1

103. Reschovsky JD, Hadley J, Landon BE: Effects of compensation methods and physician group structure on physicians' perceived incentives to alter services to patients. Health Serv Res 2006, 41 (4 Pt 1):1200-1220.

104. Kikano GE, Goodwin MA, Stange KC: Physician employment status and practice patterns. J Fam Pract 1998, 46(6):499-505.

105. PMIC: Medical Fees in the United States: Nationwide Charges for Medicare, Surgery, Laboratory, Radiology and Allied Health Services, 2010 Edition Los Angeles: Practice Management Information Corporation; 2009.

106. Casalino LP, et al: Benefits of and barriers to large medical group practice in the united states. Arch Intern Med 2003, 163(16):1958-1964.

107. Robinson JC: Physician-hospital integration and the economic theory of the firm. Med Care Res Rev 1997, 54(1):3-24.

108. Robinson JC: Consolidation of medical groups into physician practice management organizations. JAMA 1998, 279(2):144-149.

109. Robinson JC: Physician organization in California: crisis and opportunity. Health Aff 2001, 20(4):81-96.

110. Shortell SM, et al: Remaking Health Care in America: Building Organized Delivery Systems San Francisco: Jossey-Bass Publishers; 1996.

111. Ellis RP, McGuire TG: Provider behavior under prospective reimbursement. J Health Econ 1986, 5(2):129-151.

112. Harris JE: The internal organization of hospitals: some economic implications. The Bell J Econ 1977, 8(2):467-482.

113. McGuire TG: Physician Agency. In Handbook of Health Economics. Edited by: Culyer AJ, Newhouse JP. New York: Elsevier; 2000:461-536.

114. Pauly MV: Doctors and Their Workshops: Economic Models of Physician Behavior Chicago: The University of Chicago Press; 1980.

doi:10.1186/2191-1991-2-7

Cite this article as: Schneider et al:: Organizational boundaries of medical practice: the case of physician ownership of ancillary services. Health Economics Review 2012 2:7.

\section{Submit your manuscript to a SpringerOpen ${ }^{\mathcal{O}}$ journal and benefit from:}

- Convenient online submission

- Rigorous peer review

- Immediate publication on acceptance

- Open access: articles freely available online

- High visibility within the field

- Retaining the copyright to your article

Submit your next manuscript at $>$ springeropen.com 